\title{
TEACHING ETHICS AND CRITICAL THINKING IN CONTEMPORARY SCHOOLS
}

\author{
Bojan Borstner, Smiljana Gartner \\ University of Maribor, Slovenia \\ E-mail: bojan.borstner@um.si, smiljana.gartner@um.si
}

\begin{abstract}
Basic ethical questions, dilemmas and especially decisions do not only affect the life of an individual but can also affect lives of others. In some professional ethics, where decisions about a person's life or death are made, decisions can even be irreversible. In this contribution three ways of deciding by highlighting critical, and reflective decision-making or systematic thought process as the most effective method in ethics have been pointed out. Therefore, taking ethics as a critically reflective morality highlights the fact that we can talk about ethical exploration, so ethics is a process of thinking, not a set of established answers that need only to be passively accepted. It could be concluded that the study of, and practice in, evaluating arguments and evidence (moral decision making) via critical thinking as well as using other important skills (raising questions according to Blooms taxonomy and doing a lot of case studies) is the best way to achieve the most fundamental goal in teaching an ethical course-becoming a better person. And is therefore something that should be in every curriculum.
\end{abstract}

Key words: authority, critical thinking, ethics, decision-making, intuition, teaching ethics.

\section{Introduction}

On a daily basis people are confronted with questions such as "Should we euthanize our dog?", "Is disclosing personal data of another ever right or wrong?", "Am I a good person if I do not tell on a colleague who stole a tomato no one will miss?" and as a consequence to that make ethical decisions every day, which is why many people think of ethics and reasoning as part of critical thinking as unnecessary scientific disciplines and teaching of ethics and critical thinking as even less necessary since "everyone does it" anyway. Even at this very point, the usefulness of critical thinking is perfectly apparent as we can conclude with its help that "everyone does it" does not lead to a conclusion that everyone can do the abovementioned. If a person values a principle such as 'the truth must always be told', then her conviction can have implications for ethics in the dramatic, persisting and general senses. But, if a person holds an aesthetic value (if she values an opera or a novel, for instance) or another type of intangible value (perhaps she values trustworthiness) then the mere fact that she has the value does not necessarily raise dramatic or persisting ethical issues - though maintaining any value always has some bearing on a person's decision how to live her life. »We are discussing no small matter, but how we ought to live« (Plato, The Republic, 352d) Socrates states in Plato's Republic. Basic questions of ethics, answers and especially decisions do not only affect the life of an individual but can also affect the lives of others.

This is also the reason why it will be pointed out throughout the entire contribution that teaching ethics, especially teaching ethical decisions making, is a necessity in today's school in increasingly globalized world where the information and evaluation of this information on the base of ethical decision making and critical thinking become a more and more important skill for the whole life. It is therefore important that these skills become a fundamental part of the school curriculum in all levels of education. 
Bojan BORSTNER, Smiljana GARTNER. Teaching Ethics and Critical Thinking in Contemporary Schools

PROBLEMS

OF EDUCATION

IN THE $21^{\text {st }}$ CENTURY

Volume 61,2014

10

Ethical Decision-Making and Teaching Ethics

When teaching ethics we are often confronted by the question from listeners whether it is right to use conceptual phrase ethical dilemmas or moral dilemmas which is why we will, before we begin discussing ethical decision-making, answer the above question. Their use is not unambiguous among authors, as some use them as synonyms, e.g. Christian morality, Christian ethics, moral conduct, ethical conduct. In this case, both concepts refer to conduct, assessment method, rules and values of a particular group. The reason for this is most likely in the origin of both words, provided that the first, morality, originates from Latin word mores (plural of 'mos', meaning custom, habit) and the other, ethics, from a Greek word ethos (custom). Cicero in De Fato coins the term moralis as a Latin translation for the Greek ethikos: "'it relates to character, called in Greek ethos, while we usually term that part of philosophy 'the study of character,' but the suitable course is to add to the Latin language by giving this subject the name of "moral science'." (Cicero, De Fato I, 1).

Others differentiate between the two terms, namely, Kant defined ethics as "Ethica est scientia imputabilitatis actionum liberarum coram foro interno" (Kant, 1997, 27:13), a science of inner duties. He explained that understanding ethics by a doctrine of virtues is too narrow because ethics can be ascribed to angels and to God, while we cannot ascribe them virtues. For him morality is laxa or rigida (Kant, 1997) or as we can find in his Political Writings, morality is a discipline "which would teach us not how to be happy, but how we should become worthy of happiness" (Kant, 1991, p. 64)

Unlike him, B. Williams is convinced that "Morality is a special system, a particular variety of ethical thought" /.../ "It embraces a range of ethical outlooks..." (Williams, 2007, p. 45) For him the term 'morality' refers to Kant's definition of ethics connected to the concept of duty. Ethics on the other side is a much broader concept as it is comprised of elements, e.g. the discussion about the difference between secular and religious morality, not found in morality (Williams, 2007). A third way of understanding ethics can be found in McDowell's text, namely, as "a branch of philosophy related to moral theory". (McDowell, 2007, 141) Certain shades, if not contradicting decisions on the basis of which we use a certain term in a certain context, thus exist. In the continuation we will take a closer look at how this division could look like.

First possible definition of terms corresponds to two different target groups, i.e. individual vs. group, meaning we use the term morality when we are discussing virtues and principles of an individual and the term ethics when the same thing refers to a certain group. For example, Abraham's story, where an act of an individual is described as morally good or moral (individual), it also corresponds to Christian ethics (group). Second differentiation of terms is used when we wish to discuss scientific disciplines. In this case the morality is a term used for person's decision-making or decision-making of a group, one's conduct or group's conduct, while ethics is a term used for philosophical, i.e. scientific discipline dealing with studying morality and moral decision-making (which is why some call it moral philosophy). The third use of these terms is also the most obvious as both terms can have different values in the same situation, namely, inside different professional groups articles in the ethical codes indicating actions which are or are not in correspondence with the profession. For example, it might be unethical for a doctor to sleep with his adult patient (it goes against the code), however, it is not immoral (she is a consenting adult). In this case both terms refer to the individual and his judgement or his judgement based on a group, but then the term ethics refers to the narrower group (e.g. professional), while the term morality refers to broader group (e.g. society).

By now the use of terms 'ethics' and 'morality' have been clarified. In the following example the answer to the question why ethical decision-making and even teaching ethics and ethical judging should be discussed, will be explored. ${ }^{1}$

1 We define such questions as moral acceptability of euthanasia, environmental rights, justification of wars, dilemmas concerning professions, etc. as applied ethics through which usefulness of ethical judging related to certain ethical dilemmas is apparent. Together with this there are two large groups, 
The first ethics seminar or professional ethics lecture will be started with a task comprised of three steps. First, those students, who think euthanasia is an ethically acceptable action, will be asked to raise their hands and then those who think it is not. In the next step the question "Why?" will be asked what follows is, at first surprisingly, now as usual, silence. The third step is for them to think and prepare for a discussion with the opposing group. It is a simple task with which we achieve the following:

- $\quad$ Firstly, students soon realize they have different conceptions of what euthanasia is. Since everyone defines the term 'euthanasia' differently, they talk past each other, making discussion far from productive. Thus, it is pointed out, that defining terms is necessary for productive discussion.

- Secondly, in the discussion they point out the characteristics which arise in the field of medicine, economy, law, philosophy, etc., and they realize through this task that the questions of ethics arise in the fields of all scientific disciplines. Understanding problems as ethical problems inside different fields cannot be taken as granted but rather as a consequence of practicing.

- Thirdly, with the question "Why?" they are confronted with the fact that their simple answer right/wrong is not enough but needs justification and self-reflexion of the basis of our original decision. Therefore, the question and the answer which posed no real problem and did not demand any real effort from the students, soon prove to be a tough nut to crack, a dilemma which we try to solve in the following lectures or seminars.

- $\quad$ Fourthly, the described example can serve us to show that when we are making and justifying decisions we can use at least three methods we will describe in the continuation of the article.

The first method is appealing to intuitions. The decision of some of the listeners was instantaneous, perfectly spontaneous, with no thinking or reasoning. If we accept the definition of intuition as a "process that can generate attitudes and decisions, but that does not involve any conscious weighing of reasons in favour or against a particular attitude or decision" (e.g. Kahneman, 2003; Gigerenzer, 2007, in Bartoloti, 2011, p. 5), we can state their decision was intuitive. When we are discussing intuitions we can talk about different understandings of the term 'intuition'. One is the type of intuition contemporary social scientists focus on and is sometimes explained in terms of the non-conscious operation that is quick and frugal (Bartoloti, 2011). The problem of this kind of decision-making and justifying is that our intuitions can change rapidly, not only agent's (e.g. in the morning I have the intuition to vote for candidate $\mathrm{a}$, in the afternoon I have the intuition to vote for candidate b) but also among individuals (e.g. person a has the intuition that euthanasia is morally acceptable, person $b$ has the intuition it is not) and can be in discordance with commonly accepted principles in society. As they are not accepted based on reasoning, it is hard to answer why we made such a decision. They can lead to wrong decisions and are consequently strongly connected with remorse. One could speak of another kind of intuitions when understanding them as "non-inferential form of insight that builds on, and is made possible by, extensive prior experience" (e.g. Dreyfus 1997; Osbeck and Robinson 2005, in Bartoloti, 2011, p. 5). For example, being a nurse or a professional driver demands from an agent to make decisions, sometimes it even means life or death decisions in a

namely normative ethics and meta-ethics. First one, with the help of different ethical theories, gives answers to what ethical thinking even means and how it works, i.e. how we should live, what we should do, how we can make certain ethical decisions, all independently from topic. Questions such as "Are we entitled to make certain ethical judgements?" and "Are phrases 'ethically right', 'ethically wrong', 'good', 'bad' identical to the facts in the world or not?" are related to ethics itself which is why they fall under meta-ethics. All three areas are, if at all, hardly separable, which is why ethics as a whole is so much more complex.

$\mid$\begin{tabular}{l} 
PROBLEMS \\
OF EDUCATION \\
IN THE 21 $1^{\text {st }}$ CENTURY \\
Volume 61, 2014 \\
\hline 11
\end{tabular}

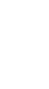


Bojan BORSTNER, Smiljana GARTNER. Teaching Ethics and Critical Thinking in Contemporary Schools

PROBLEMS

OF EDUCATION

IN THE $21^{\text {st }}$ CENTURY

Volume 61,2014

12

matter of seconds. Therefore, they claim their decision was not based on reflection who else is involved, how and who the alternative options will affect and reasoning and choosing the best alternative, but rather on intuition. However, when we speak about an expert, we speak about someone with years of experience in his professional field, which means that his past decisions, contemplating on good and bad consequences of decisions made and thinking about alternative options, will serve as the basis of ever faster, decreasingly risky decision-making or, as Dreyfus (1992) states that "with talent and a great deal of involved experience the beginner develops into an expert who sees intuitively what to do without applying rules and making judgements at all". Such intuitive decision-making of experts is mostly correct, even if it was quick and frugal. However, we must not forget, it is a consequence of years long effort, an enormous amount of time invested in reflecting about decisions and possibly lingering presence of remorse if decision was not the best. $^{2}$

The second method is to appeal to authority. By doing this, moral responsibility for the consequences of our actions is at least partly taken from our shoulders. Listeners could decide that euthanasia is morally unacceptable and justify their decision by stating that this is what their professor said or that it is written in the law or in the ethical code. ${ }^{3}$ If we appealed to one of the above mentioned possibilities, we could get to know the problems of appealing to authority. ${ }^{4}$ These are: (i) we can easily commit a fallacy. What we mean by that is that the code of ethics or the person we are appealing to, is not an expert in the field we are referring to or that the code of ethics does not apply to the referred field. If, for example, we appeal to an astronomer when discussing euthanasia, we are talking about a fallacy or fallacious justification. (ii) Uncritically accepting an expert or a code of ethics means that we are excluding the possibility of them being mistaken, which can be a mistake on our part. For science this would mean non-progress, since, if we believed the authorities proving that the earth is flat and we can fall from its edges, we would not have seafarers who wanted to explore and would not have the contemporary theory claiming that the earth is an ever changing oblate spheroid, a theory again rejected by some..$^{5}$ (iii) Experts or articles of an ethical code of optional professional ethics can be, referring to a concrete example, unclear in answering what to do or even contradictory. Even if codes comprise rules, the interpretation is necessary. Besides, they cannot cover each situation and cannot give unambiguous answer for each situation. For example, in $8^{\text {th }}$ bullet point of $5^{\text {th }}$ principle of The Code of Ethics for nurses and health technicians it is written: "A nurse does not perform procedures for which she does not have the adequate competences and experience" (2005) and in $7^{\text {th }}$ that she must not deny medical assistance suitable for her professional qualification. In case she should perform $X$ according to her professional qualification but lacks experience, which standard should be more important? Therefore, if the agent relentlessly sticks to the ethical code, he might be confronted with "a decision that falls outside of the code of ethics for their profession", which means he "will be ill-equipped with allegiance to moral relativism, likely not possessing the necessary tools to make a reasoned, defensible decision. It is troubling to think of a future professional, especially one who is faced with a life and death decision, adopting a relativist stance towards their professional ethical decisions" (Jones, 2009, p. 46).

The third method is to use systematic, critical judging where reason is the basic tool. Employing the process of reasoning and this type of judging enable a firm basis on which other individuals can assess the decision and on the basis of which we can ascribe moral responsibility to those involved. Namely, if a person values a principle such as 'the truth must always be

2 Third understanding of the term "intuition" is: clear and dependable insight into something. The consequence of this type of intuition is a decision that is always right or, for example in mathematics, a correctly solved problem.

3 Ethical codes are documents, adopted by institutions or experts in certain professional field in order to help their members understand what is good or bad, ethically (un)acceptable, (un)wanted and (non)binding in relation to participants.

$4 \quad$ We could commit the so-called Appeal to authority (lat. ad verecundiam).

5 The International Flath Earth Society. 
told', then her conviction can have implications for ethics in the dramatic, persisting and general senses. Thus, the decision made does not affect only the agent but also other people, which

is why the last method is most effective - but not necessarily most simple or most welcome. This, maybe, is the reason that a person of virtue, a person living in accordance to ethics, a good person is valued so highly or even admired. Aristotle (2002) states such person:

- $\quad$ Firstly, projects human nature itself;

- Secondly, acts in accordance with decisions and virtues, which is hard. A person must put much effort into such behaviour, i.e., it must possess much will power to avoid faults or "temptation" to act differently. This means that desires and will power must be regulated in certain situations;

- Together with desire and will power the use of reason is a necessary element. Reason and thinking help her recognize and understand a situation, recognize relevant characteristics and find reasons for or against certain action. This helps him act prudently (gr. phronesis).

It could be concluded that if acting in accordance to virtues and values is projecting human nature itself, if it means a good and happy life and consequent good and content society, then moral progress through exploring or critical thinking is a necessary element of each educational institution. Up to this point we have explained why we should understand ethics as a thinking process and why we should use the third method, i.e. systematic ethical judging. We will take a look at how we can do that in the next part of the article.

\section{Critical Thinking in Ethical Decision-Making and in Teaching Ethics}

Virtues and moral values are therefore something that can be attained by an individual. The activity of an individual using reason is an important element. Sole use of reason is not enough that is why, as we have mentioned in the first part of this article, we need to understand ethics as a construction of a critically reflective morality. It is critical since it leaves itself open to examining and re-examining reasons from all sources and disciplines. And it is reflective since a conscientious moral agent is constantly trying to achieve a delicate balance that takes into account the effect of these reasons on his or her deepest values. (Card, 2002) Because ethics is not a single body of knowledge about what is right and wrong, taking ethics as a critically reflective morality highlights the fact that ethics is a process of thinking, not a set of established answers that need only to be passively accepted.

This attitude is based on the assumption that ethics does not consist in knowing the answers but instead in knowing how to inquire:

- $\quad$ in knowing what counts as a possible answer;

- what questions are appropriate and constructive ones to ask;

- what tendencies in one's own thinking need to be kept in check, etc.

Most treatments of ethics (professional ethics are included) assume that the most helpful skills to develop are those of identifying and resolving ethical problems using arguments, which presents the most important part of teaching critical thinking. Before we begin discussing the role of critical thinking in ethics and in teaching ethics, we will in short present what it is that we understand under this term. Critical thinking is: complex thinking; evaluating what we hear and read; finding reasons to confirm or reject something else; recognizing fallacious reasoning and fallacies. Thus critical thinking enables:

- $\quad$ precise thinking and expressing when analysing and formulating complex and controversial moral problems. 
Bojan BORSTNER, Smiljana GARTNER. Teaching Ethics and Critical Thinking in Contemporary Schools

\section{PROBLEMS \\ OF EDUCATION \\ IN THE $21^{\text {st }}$ CENTURY \\ Volume 61,2014}

- $\quad$ recognizing individual situations;

- deepening person's understanding of his own moral experience (judgement, emotions, actions) and the ability to clearly and precisely express it.

- $\quad$ possibility to react differently to a given problem;

- indeterminate answers, which means that, at least at the initial stage, we are avoiding

- phrases such as "correct answer", "right solution".

Critical thinking means doubting and having many different ideas. If we had to describe all of the above with a phrase we might be successful with a phrase "process of exploring". Therefore thinking, which also encompasses critical thinking, is a process, is exploration.

There are several methods how to nourish, stimulate and enhance ethical exploration or critical thinking in ethics or teaching ethics. One method is learning techniques of critical thinking (e.g. logical rules), which can be, when dealing with formal logic, "very dull and useless" for some people. Certainly, these skills are crucial, and fostering them should be a central goal in any professional ethics course. However, this is not enough for ethical exploration.

The second method is asking question as we can stir doubt in individual and stimulate developing ideas and asking questions. In deciding which questions we should use (according to goals we wish to achieve with people) Bloom's taxonomy of learning aims for cognitive area (1956) can be very helpful. Bloom's taxonomy':

- $\quad$ Knowledge (data, formulas, facts)

- Comprehension (recognizing meaning and events, interpretation of information)

- Application (use of information to solve problems)

- $\quad$ Analysis, (recognizing patterns, parts, elements)

- Synthesis (choosing elements, judgement) and

- $\quad$ Evaluation (generalization, deriving conclusions).

According to Milleti, $\gg$ Bloom's taxonomy, particularly in its new verb-based form (Remember, Comprehend, Apply, Analyse, Evaluate, Create) is useful, but may not be sufficient." (Milleti, 2002, p. 63) There is a cluster of other important skills that professionals and preprofessionals should acquire if they are going to manage ethical issues successfully in real-life professional contexts. Following Leever (2001) the first skill is simply the ability to identify the causal sources of ethical problems. Ethical problems are always better avoided than solved. Being able to identify the causes of an ethical misconduct and ethical dilemmas is the first important step in preventing them. The second is to focus on one particularly common cause of ethical problems. Many ethical problems are caused by a poor communication or a lack of communication. Understanding what morality requires in any given circumstance is not enough. The third skill is operationalizing moral values, which often requires superior communication and interpersonal skills. Without such a skill, even the keenest moral intellect will be ineffective. Here is an additional reflection on the importance of the effective communication: professionals often speak to one another about ethical issues, but they rarely do so with a sufficient specificity. Because of this, the values that are ultimately at stake remain obscured by a vague (and sometimes ambiguous) ethical language. Hence, sharpening a communication is an important goal of a professional ethics education: it does not merely prevent ethical problems, but also allows professionals to converse efficiently about them, thereby increasing the likelihood that they will be resolved. Using case studies is an effective way for reaching this goal.

The framework for thinking ethically and for teaching thinking ethically at professional ethics courses that we find very useful when analysing case studies is the product of a dialogue and debate at the Markkula Center for Applied Ethics at Santa Clara University. It consists of

6 We took into account the order of objectives and competences of cognitive domain according to the revised Bloom's taxonomy, where the objectives of 'creating (synthesis)' and 'evaluation' are swapped. The objectives 'analysis', 'evaluation' and 'creation (synthesis)' do not necessarily follow hierarchical order as they can also be parallel one to another. 
several elements and could be nicely connected with the idea of the Asking questions method of teaching. It consists of the following elements ${ }^{7}$ :

- Recognize an ethical issue: Is this an ethical issue? Why? Could this decision or situation be damaging to someone or to some group? Does this decision involve a choice between a good and bad alternative? Between two "goods"? Between two "bads"?

- Collect the facts: What are the relevant facts of the case? What facts are not known?; Do I know enough to make a decision?; What individuals and groups have an important stake in the outcome?; Are some concerns more important? Why?

- $\quad$ Collect the options: What are the options for acting?

- Evaluate alternative options/actions: Which option produces the most good and does the least harm; respects rights best, treats people equally? Why?

- Make a decision and test it: Considering all these approaches, which option addresses the situation best?

- $\quad$ Act and reflect on the outcome: How did my decision turn out for all stakeholders and what have I learned from this specific situation?

As we can see, developing critical thinking and stimulating exploration is not just asking any questions. There is no need for that. What matters is the activity itself taking place in the course of events, i.e. stimulating explanation, interpretation, looking for causes, etc.

Promoting the development of critical thinking skills the paper supports the very enterprise of helping students to become (better) ethical thinkers, given this substantive conception of ethics as a critically reflective morality aimed at identifying, examining, and addressing practical problems. Case studies can therefore help to improve communication skills to avoid some common ethical problems as well as help to develop skills for ethical exploration or critical thinking in ethics.

\section{Summing-up}

Based on our experience from teaching ethics and professional ethics it is obviously, that thinking about ethics, clarifying the conceptual phrases ethical vs. moral decision-making, ethical dilemmas and solving them are very important skills for anyone in today's school in increasingly globalized world, where the information and evaluation of this information on the base of ethical decision making and critical thinking become a more and more important skill for the whole life of each individual. Considering that some ethical decisions are irreversible, that life or death decisions are made, three ways of making decisions must be highlighted when teaching ethics. In this contribution it has been pointed out appealing to intuitions, appealing to authority and critical, reflective decision-making, which, opposed to the first two, at least beginners, enables us to (i) make only a few mistakes, (ii) possibility of justifying the decision and reflection and (iii) most importantly, the possibility to ethical exploration and to develop into an expert.

7 Dreyfus and Dreyfus (1986); Dreyfus, H. L. (1992) develop five stages of skill acquisition, where the final, i. e. the fifth stage is The Expert. The expert has an intuitive understanding of the situation, without applying rules and making judgements. Previous four are: 1. the novice: is given strict rules by instructor how to respond to context-free features, relies on surface features of the situation; 2. the advanced beginner: starts to recognize components of situation but cannot discriminate between relevant and irrelevant features; 3 . the competent: no one is giving her/him any rules, $\mathrm{s}(\mathrm{he})$ is recognizing relevant features, a hierarchical view of decision-making; 4. the proficient: sees situations holistically and arrives at her judgment by exercising her perceptual skills. All first four are deliberating and making analytical decision. The last one, the fifth one has an intuitive understanding of situation. 
Bojan BORSTNER, Smiljana GARTNER. Teaching Ethics and Critical Thinking in Contemporary Schools

PROBLEMS

OF EDUCATION

IN THE $21^{\text {st }}$ CENTURY

Volume 61,2014

The study and practice of moral decision making via critical thinking as well as teaching and using other important skills (raising questions according to Blooms taxonomy and doing a lot of case studies) is the best way to achieve the most fundamental goal in teaching an ethical course - becoming a better man in this world. And from this reason, it must be a part for every school curricula.

\section{Acknowledgments}

The authors acknowledge the support of the Ministry of Education, Science and Sport of Republic of Slovenia and European Social Fund in the frame of Project: "Innovative pedagogy 1: 1 in the light of competences of the 21st century" on Faculty of Natural Sciences of University of Maribor.
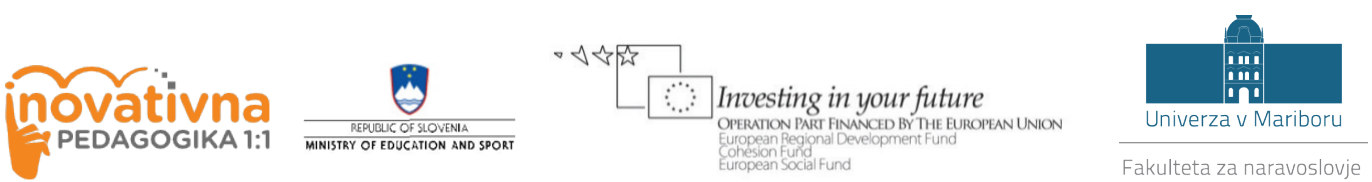

in matematiko

\section{References}

Aristotle (2004). The Nicomachean ethics (J. A. K. Thomson, Trans.). London (etc.): Penguin Books.

Bartoloti, L. (2011). Does reflection lead to wise choices? Philosophical Explorations, 14 (3), 297-313.

Card, R. F. (2002). Using case studies to develop critical thinking skills in ethics course. Teaching Ethics, $19-27$.

Cicero. De Fato (H. Rackman, Trans.). Retrieved May 30, 2014, from www.informationphilosopher.com/ solutions/philosophers/cicero/de_fato_english.html

Dreyfus, H. L. (1992). What is moral maturity? A phenomenological account of the development of ethical expertise. In J. Ogilvy (ed.), Revisioning Philosophy. Albany: State University of New York.

Dreyfus, H., Dreyfus, S. (1986). Mind over machine: The power of human intuitive expertise in the era of the computer. New York: Free Press.

Jones, C. (2009). Moral relativism, cultural awareness and cooperative learning in teaching professional ethics. Teaching Ethics, Fall, 43-50.

Kant, I. (1997). Lectures on ethics (P. Heat, Trans.). P. Heath and J. B. Schneewind (eds.), Cambridge: Cambridge University Press.

Kant, I. (1991). Political writings. H. S. Reis (ed.), Cambridge: Cambridge University Press.

Kodeks etike medicinskih sester in zdravstvenih tehnikov Slovenije (Code of Ethics for Nurses and Health Technicians) - 2005. (21. 5. 2005). Uradni list RS, št. 40/2010. Retrieved February 11, 2013, from http://www.uradni-list.si/1/content?id=97901

Leever, M. G. (2001). Teaching professional ethics: Fostering some overlooked skills. Teaching Ethics, Fall, 77 -89.

McDowell, J. (2007). Virtue and reason. In M. Slote and R. Crisp, R. (ed.), Virtue Ethics. Oxford: Oxford University Press, p. 141-162.

Millett, S. (2002). Teaching ethics (and Metaphysics) in an age of rapid technological convergence. Teaching Ethics, Spring, 53-68.

Plato (1961). The Republic. In E. Hamilton and C. Huntington (eds.) (1961), The collected dialogues of Plato. Princeton: Princeton University Press.

The International Flath Earth Society (1. 1. 2014). Retrieved July 5, 2014, from www.tfes.org

The Markkula Center for Applied Ethics at Santa Clara University. Retrieved May 20, 2014, from http:// www.scu.edu/ethics/practicing/decision/making.pdf

Williams, B. (2007). Morality, the Peculiar Institution. In M. Slote and R. Crisp, R. (ed.), Virtue Ethics, Oxford: Oxford University Press, p. 45-65.

Advised by Boris Aberšek, University of Maribor, Slovenia 
Bojan BORSTNER, Smiljana GARTNER. Teaching Ethics and Critical Thinking in Contemporary Schools

PROBLEMS

OF EDUCATION

IN THE $21^{\text {st }}$ CENTURY

Volume 61, 2014

Received: June 29, 2014

Accepted: August 20, 2014

17

Bojan Borstner $\quad$ PhD., Professor, University of Maribor, Koroška cesta 160, 2000 Maribor, Slovenia. E-mail: bojan.borstner@um.si,

Website: http://www.ff.uni-mb.si

Smiljana Gartner PhD., Associate Professor, University of Maribor, Koroška cesta 160, 2000 Maribor, Slovenia.

E-mail: smiljana.gartner@um.si 